\title{
Faktor yang Berhubungan dengan Penggunaan APD pada Pekerja Teknisi Mesin di PT PLN Rayon Tembilahan
}

\author{
Firman Edigan¹, Deny Pratama Putra ${ }^{2}$ \\ ${ }^{1}$ Dosen Prodi lmu Kesehatan Masyarakat, STIKes Hang Tuah Pekanbaru \\ ${ }^{2}$ Mahasiswa Prodi lmu Kesehatan Masyarakat, STIKes Hang Tuah Pekanbaru
}

\begin{abstract}
Abstrak
PT PLN Rayon Tembilahan adalah perusahaan yang bergerak di bidang penyediaan tenaga listrik, pada penelitian awal terdapat pekerja pada shift siang masih banyak pekerja yang tidak menggunakan APD dengan lengkap sesuai dengan bagian pekerjaanya. Tujuan penelitian ini untuk mengetahui hubungan pengetahuan pekerja, kondisi lingkungan, ketersediaan sarana, pengawasan terhadap penggunaan APD pada pekerja teknisi mesin di PT PLN Rayon Tembilahan. Metode penelitian yang digunakan adalah penelitian kuantitatif dengan desain penelitian Cross Sectional. Sampel dalam penelitian ini menggunakan total sampling dimana pekerja teknisi mesin di PT PLN Rayon Tembilahan yang berjumlah 35 orang. Analisis data secara univariat dan bivariat dengan uji-square. Hasil penelitian yang diperoleh tidak ada hubungan pengetahuan dengan penggunaan APD dengan nilai $\mathrm{p}=0,899$, adanya hubungan kondisi lingkungan dengan penggunaan APD dengan nilai $\mathrm{p}=0,022$ dan diperoleh nilai $\mathrm{OR}=8,500$, adanya hubungan sarana prasarana dengan penggunaan APD dengan nilai $\mathrm{p}=0,031$ dan diperoleh nilai $\mathrm{OR}=6,857$, tidak ada hubungan pengawasan dengan penggunaan APD dengan nilai $\mathrm{p}=0,854$ dan diperoleh nilai $\mathrm{OR}=1,429$. Diharapkan kepada pihak PLN Rayon Tembilahan agar memperihatikan kondisi lingkungan kerja dan bisa melengkapi sarana prasarana untuk pekerja agar dapat mengurangi resiko terhindar dari kecelakaan kerja.
\end{abstract}

Kata Kunci : Pengetahuan, Pekerja, APD, Risiko, Kecelakaan Kerja

\begin{abstract}
PT PLN Rayon Tembilahan is a company in the provision of electric power, In the initial study there are workers in the afternoon shift there are still many workers who do not use the complete PPE related with their work, the purpose of this study to determine the relationship of worker knowledge, environmental conditions, the availability of facilities, supervision of the use of PPE on workers in the engine technician PT PLN Rayon Tembilahan. The research method used is quantitative research with Cross Sectional research design. The sample in this research use total sampling where machine technician workers in PT PLN Rayon Tembilahan which amounted to 35 person. Univariate and bivariate data analysis with square test. The result of this research is no correlation with the use of PPE with $p=0,899$, there is relation of environmental condition with PPE usage with $p$ value $=0,022$ and obtained value $O R=8,500$, there is correlation of facility of infrastructure by using PPE with $p$ value $=0,031$ and Value $O R=6.857$, there is no relationship of supervision with the use of PPE with the value $p=0.854$ and obtained the value OR $=1.429$. It is expected to PLN Rayon Tembilahan to envisage the condition of the work environment and can equip the infrastructure for workers to reduce the risk of avoidance of work accident.
\end{abstract}

Keywords : Knowledge, Worker, PPE, Risk, Work accident 
Dengan berkembangnya teknologi dan industri, tanpa disadari telah meningkatkan pula jumlah kecelakaan kerja yang terjadi, khususnya di dalam kegiatan industri. Kecelakaan-kecelakaan tersebut telah menyebabkan kerugian yang besar, termasuk jiwa, harta, benda, bahkan berpengaruh terhadap ekonomi secara umum. Banyak kecelakaan industri yang terjadi disebabkan karena kurangnya pengetahuan pekerja tentang bahaya-bahaya yang menyebabkan kecelakaan (Rijanto, 2011: 287).

Menurut data dari International Labour Organization Setiap tahun ribuan kecelakaan terjadi di tempat kerja yang menimbulkan korban jiwa, kerusakan materi, dan gangguan produksi. Setiap hari terjadi sebanyak 6.000 kecelakaan kerja fatal di dunia. Di Indonesia sendiri terdapat kasus kecelakaan kerja yang setiap harinya dialami para buruh setiap 100 ribu tenaga kerja dan $30 \%$ diantaranya terjadi di sektor kontruksi (ILO, 2015).

Menurut data dari Badan Penyelenggara Jaminan Sosial ketenagakerjaan (BPJS), kasus kecelakaan kerja tahun 2015 menurun menjadi 50.089 kasus, yang pada tahun sebelumnya mencapai 53.319 kasus, dan tahun 2011 sebanyak 99.491 kasus (BPJS, 2015). Menurut Ocupational Safety and Health Administration, OSHA(2016) Setiap pekerjaan selalu mengandung potensi risiko bahaya dalam bentuk kecelakaan kerja. Besarnya potensi kecelakaan dan penyakit kerja tersebut tergantung dari jenis produksi, teknologi yang dipakai, bahan yang digunakan, tata ruang dan lingkungan bangunan serta kualitas manajemen dan tenaga tenaga pelaksana.

Jumlah kasus kecelakaan akibat kerja tahun 2011-2014 yang paling tinggi pada 2013, yaitu 35.917 kasus kecelakaan kerja (Tahun $2011=9.891$; Tahun $2012=21.735$; Tahun $2014=24.910$ ). Propinsi dengan jumlah kasus kecelakaan akibat kerja tertinggi pada tahun 2011 adalah Propinsi Banten, Kalimantan Tengah dan Jawa Timur; Tahun
2012 adalah Propinsi Jambi, Maluku dan Sulawesi Tengah; Tahun 2013 adalah Propinsi Aceh, Sulawesi Utara dan Jambi; tahun 2014 adalah Propinsi Sulawesi Selatan, Riau dan Bali.

Alat Pelindung Diri (APD) sangat berperan penting terhadap kesehatan dan keselamatan kerja. Alat pelindung diri merupakan seperangkat alat yang di gunakan oleh tenaga kerja untuk melindungi seluruh atau sebagian tubuhnya terhadap kemungkinan adanya potensi bahaya di tempat kerja atau kecelakaan kerja (Kurniawati, 2013: 33-35). Pekerja yang menggunakan APD tidak secara sempurna dapat melindungi tubuhnya, tetapi akan dapat mengurangi tingkat keparahan yang mungkin terjadi dan pekerja yang tidak menggunakan APD saat bekerja dapat menyebabkan kecelakaan kerja pada pekerja dan mengakibatkan korban jiwa, cacat, kerusakan peralatan, menurunnya mutu dan hasil produksi dan akhirnya akan terjadi kerugian pada pabrik.

Berdasarkan observasi lapangan di PT PLN Rayon Tembilahan pada bagian teknisi mesin masih ada ditemukan pekerja yang tidak menggunakan APD. Hal ini dapat menyebabkan parahnya kondisi pekerja jika terjadinya kecelakaan, serta berisiko mengakibatkan penyakit akibat kerja pada pekerja bagian teknisi mesin, seperti pekerja yang tidak menggunakan ear plug dalam melakukan pengecekan mesin yang bisa menyebabkan rusaknya pendengaran, tidak menggunakan masker untuk mengurangi debu dan asap yang berasal dari knalpot mesin diesel ataupun ruangan mesin yang apabila terhirup dapat menyebabkan gangguan pernapasan, radang paru-paru dan penyakit lainnya. Oleh karena itu peneliti tertarik melakukan penelitian dengan judul "faktor yang berhubungan dengan perilaku penggunaan APD pada pekerja bagian pengolahan di PT PLN Rayon Tembilahan".

\subsection{Rumusan Masalah}

Pekerja teknisi mesin PT PLN Rayon merupakan pekerjaan yang berisiko 
terjadinya kecelakaan kerja dan penyakit akibat kerja. Lingkungan kerja dan kelalaian kerja dalam bekerja dan tidak mengunakan alat pelindung diri (APD) berpotensi terhadap semakin parahnya kondisi pekerja jika terjadi kecelakaan kerja, sehingga dibutuhkan penelitian tentang "faktor yang berhubungan dengan sikap penggunaan APD pada pekerja bagian teknisi mesin di PT PLN Rayon Tembilahan”.

\subsection{Pertanyaan Penelitian}

1. Bagaimana pengetahuan pekerja terhadap penggunaan APD pada pekerja di bagian teknisi mesin PT PLN Rayon Tembilahan?

2. Bagaimana kondisi lingkungan kerja terhdap penererapan pengunaan APD pada pekerja bagian di bagian teknisi mesin PT PLN Rayon Tembilahan?

3. Bagaimana ketersediaan sarana terhadap penggunaan APD pada pekerja bagian teknisi mesin PT PLN Rayon Tembilahan?

4. Bagaimana tentang pengawasan perusahaan terhadap penggunaan APD pada pekerja di bagian teknisi mesin PT PLN Rayon Tembilahan?

\subsection{Tujuan Penelitian}

Tujuan yang akan dicapai dalam penelitian yang dilakukan, adalah :

\section{Tujuan Umum}

Untuk Mengatahui Faktor yang Berhubungan dengan Pengunaan APD pada Pekerja Bagian Teknisi Mesin di PT PLN Rayon Tembilahan 2017.

\section{Tujuan Khusus}

a. Untuk Mengetahui hubungan pengetahuan pekerja terhadap penggunaan APD pada pekerja kuantitatif dengan menggunakan desain Croos Sectional, yaitu penelitian dilakukan untuk melihat hubungan variabel sebab dan akibat yang diukur dalam satu waktu tertentu bagian teknisi mesin PT PLN Rayon Tembilahan.

b. Untuk Mengetahui hubungan kondisi lingkungan kerja terhadap penggunaan APD pada pekerja bagian teknisi mesin PT PLN Rayon Tembilahan.

c. Untuk Mengetahui hubungan ketersediaan sarana terhadap penggunaan APD pada pekerja bagian teknisi mesin PT PLN Rayon Tembilahan.

d. Untuk Mengetahui hubungan antara pengawasan perusahaan terhadap penggunaan APD pada pekerja bagian teknisi mesin PT PLN Rayon Tembilahan.

\subsection{Manfaat Penelitian}

1. Bagi PLN

Dapat dijadikan sebagai bahan masukan dan pertimbangan bagi pihak-pihak yang berkepentingan dalam pengunaan APD dan pentingnya program K3 bagi perusahaan.

2. Bagi Akademik

Memberikan bahan, wacana, dan pemikiran bagi pengembangan dan penerapan ilmu kesehatan masyarakat terutama di bidang keselamatan dan kesehatan kerja (K3) bagi mahasiswa dan Perpustakaan STIKes Hang Tuah Pekanbaru.

3. Bagi Peneliti

Memperoleh kesempatan dalam menerapkankan perkuliahan dan menambah wawasan serta pengetahuan dibidang kesehatan masyarakat khususnya keselamatan dan kesehatan kerja (K3).

\section{METODE PENELITIAN}

Penelitian ini dilaksanakan di PT PLN Rayon Tembilahan Kabupaten Indragiri Hilir Jenis penelitian ini adalah penelitian populasi yang diambil adalah jumlah pekerja bagian teknisi yang ada di PT PLN Rayon Tembilahan Inhil yang berjumlah 35 orang yang dibagi menjadi 2 shift siang dan malam 
Teknik sampling yang digunakan yaitu teknik keseluruhan total sampling variabel Independen dalam penelitianini adalah Pengetahuan, sikap, ketersediaan sarana dan pengawasan Variabel Dependen penelitian ini adalah penggunaan alat pelindung diri (APD).

\section{HASIL DAN PEMBAHASAN}

\section{HASIL}

\section{Analisis Univariat}

\section{a. Alat Pelindung Diri (APD)}

Tabel 1. Distribusi Alat Pelindung Diri pada Pekerja Teknisi Mesin di PT PLN Rayon Tembilahan

\begin{tabular}{clcc}
\hline No. & $\begin{array}{c}\text { Alat Pelindung } \\
\text { Diri (APD) }\end{array}$ & Jumlah & $\begin{array}{c}\text { Persentase } \\
(\mathbf{\%})\end{array}$ \\
\hline 1. & Kurang Baik & 19 & 54.3 \\
2. & Baik & 16 & 45.7 \\
\hline & Jumlah & $\mathbf{3 5}$ & $\mathbf{1 0 0 . 0}$ \\
\hline
\end{tabular}

Berdasarkan Tabel 1, diketahui bahwa sebagian besar responden dalam menggunakan APD yang baik sebanyak 19 (54.3\%) pekerja.

\section{b. Pengetahuan}

Tabel 2. Distribusi Pengetahuan pada Pekerja Teknisi Mesin di PT PLN Rayon Tembilahan.

\begin{tabular}{clcc}
\hline No. & \multicolumn{1}{c}{ Pengetahuan } & Jumlah & $\begin{array}{c}\text { Persentase } \\
(\mathbf{\%})\end{array}$ \\
\hline 1. & Kurang Baik & 19 & 54.4 \\
2. & Baik & 16 & 45.6 \\
\hline & Jumlah & $\mathbf{3 5}$ & $\mathbf{1 0 0 . 0}$ \\
\hline
\end{tabular}

Berdasarkan Tabel 2, diketahui bahwa mayoritas pengetahuan yang kurang baik sebanyak 19 (54.4\%) pekerja.

\section{c. Kondisi lingkungan kerja}

Tabel 3. Distribusi Kondisi Lingkungan Kerja pada Pekerja Teknisi Mesin di PT PLN Rayon Tembilahan.

\begin{tabular}{clcc}
\hline No. & $\begin{array}{c}\text { Kondisi Lingkungan } \\
\text { Kerja }\end{array}$ & Jumlah & $\begin{array}{c}\text { Persentase } \\
(\mathbf{\%})\end{array}$ \\
\hline 1. & Kurang Baik & 25 & 71.4 \\
2. & Baik & 10 & 28.6 \\
\hline & Jumlah & $\mathbf{3 5}$ & $\mathbf{1 0 0 . 0}$ \\
\hline
\end{tabular}

Berdasarkan Tabel 3, diketahui bahwa mayoritas kondisi lingkungan yang kurang baik sebanyak 25 (71.4\%) pekerja.

\section{d. Ketersediaan Sarana}

Tabel 4. Distribusi Ketersediaan Sarana pada Pekerja Teknisi Mesin di PT PLN Rayon Tembilahan.

\begin{tabular}{clcc}
\hline No. & Ketersediaan Sarana & Jumlah & $\begin{array}{c}\text { Persentase } \\
(\mathbf{\%})\end{array}$ \\
\hline 1. & Kurang Baik & 23 & 65.7 \\
2. & Baik & 12 & 34.3 \\
\hline & Jumlah & $\mathbf{3 5}$ & $\mathbf{1 0 0 . 0}$ \\
\hline
\end{tabular}

Berdasarkan Tabel 4, diketahui bahwa mayoritas ketersediaan sarana yang kurang baik sebanyak $23(65.7 \%)$ pekerja.

\section{e. Pengawasan}

Tabel 5. Distribusi Pengawasan Pada Pekerja Teknisi Mesin di PT PLN Rayon Tembilahan.

\begin{tabular}{clcc}
\hline No & Pengawasan & Jumlah & $\begin{array}{c}\text { Persentase } \\
(\boldsymbol{\%})\end{array}$ \\
\hline 1. & Baik & 18 & 51.4 \\
2. & Kurang Baik & 17 & 48.6 \\
\hline & Jumlah & $\mathbf{3 5}$ & $\mathbf{1 0 0 . 0}$ \\
\hline
\end{tabular}

Berdasarkan Tabel 5, diketahui bahwa mayoritaspengawasan yang baik sebanyak $18(51.4 \%)$ pekerja.

\section{Analisis Bivariat}

\section{a. Hubungan Pengetahuan Terhadap Pengunaan Alat Pelindung Diri}

Tabel 6. Hubungan Pengetahuan Terhadap Pengunaan Alat Pelindung Diri pada Pekerja Teknisi Mesin di PT PLN Rayon Tembilahan.

\begin{tabular}{|c|c|c|c|c|c|c|c|}
\hline \multirow[b]{2}{*}{ 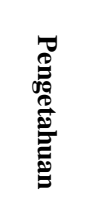 } & \multicolumn{4}{|c|}{ Alat Pelindung Diri } & \multirow[b]{2}{*}{$\overrightarrow{0}$} & \multirow{2}{*}{ 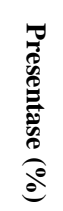 } & \multirow[b]{2}{*}{ ه } \\
\hline & 苐: & 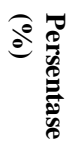 & 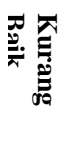 & 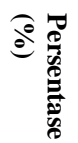 & & & \\
\hline Baik & 8 & 50.0 & 8 & 50,0 & 16 & 100 & \\
\hline $\begin{array}{l}\text { Kurang } \\
\text { baik }\end{array}$ & 8 & 42,1 & 11 & 57,9 & 19 & 100 & $\begin{array}{l}8 \\
0 \\
0 \\
0\end{array}$ \\
\hline Total & 16 & 45,7 & 19 & 54,3 & 35 & 100 & \\
\hline
\end{tabular}


Berdasarkan Tabel 6, diketahui bahwa dari 16 pekerja dengan pengetahuan baik dalam pengunaan APD sebanyak 8 baik dan tidak baik sebanyak 8 pekerja dan dari 19 pekerja dengan pengetahuan yang kurang baik sebanyak 11 pekerja dengan pengetahuan baik sebanyak $8(42,1 \%)$ pekerja dan kurang baik sebanyak 11 (57,9\%).

Hasil uji chi-square diperoleh nilai $(0,899$ > $0,05)$ artinya tidak adanya hubungan antara pengetahuan dengan penggunaan APD pada pekerja teknisi mesin di PT PLN Rayon Tembilahan. Dari hasil uji statistik diperoleh nilai OR $(95 \% \mathrm{Cl})=1.375(0.361-5.240)$ artinya menunjukan bahwa pengetahuan mempunyai peluang 1 kali berisiko dalam penggunan APD.

\section{b. Hubungan Kondisi Lingkungan atau Kondisi Kerja Terhadap Penggunaan Alat Pelindung Diri}

Tabel 7. Hubungan Kondisi Lingkungan Terhadap Pengunaan Alat Pelindung Diri pada Pekerja Teknisi Mesin di PT PLN Rayon Tembilahan.

\begin{tabular}{|c|c|c|c|c|c|c|c|}
\hline \multirow{2}{*}{ 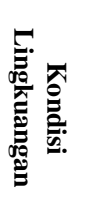 } & \multicolumn{4}{|c|}{ Penggunaan APD } & \multirow[b]{2}{*}{$\overrightarrow{0}$} & \multirow{2}{*}{ 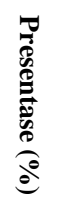 } & \multirow[b]{2}{*}{ 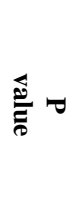 } \\
\hline & 苛. & 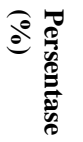 & 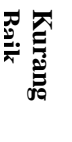 & 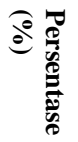 & & & \\
\hline Baik & 8 & 80.0 & 2 & 20.0 & 10 & 100 & \\
\hline $\begin{array}{l}\text { Kurang } \\
\text { baik }\end{array}$ & 8 & 32.0 & 17 & 68.0 & 25 & 100 & i \\
\hline Total & 16 & 45.7 & 19 & 54.3 & 35 & 100 & \\
\hline
\end{tabular}

Berdasarkan Tabel 7, diketahui bahwa ada 10 pekerja mengatakan kondisi lingkungan para pekerja yang baik dalam pengunaan APD sebanyak 8 (80.0\%) dan yang kurang baik dalam pengunaan APD sebanyak 2 $(20.0 \%)$, dan 25 pekerja mengatakan kondisi lingkungan yang kurang baik dalam pengunaan APD sebanyak $8(32.0 \%)$ baik dan kurang baik 17 (68,0\%).

Hasil uji chi-square diperoleh nilai $(0,022<$ $0,05)$ artinya adanya hubungan antara kondisi lingkungan dengan penggunaan APD pada pekerja teknisi mesin di PT PLN Rayon Tembilahan. Dari hasil uji statistik diperoleh nilai OR $(95 \% \mathrm{Cl})=8.500(1.458$ 49.539) artinya menunjukan bahwa kondisi lingkungan yang kurang baik mempunyai peluang 9 kali berisiko dalam menggunakan APD.

\section{c. Hubungan Ketersediaan Sarana dengan Pengunaan Alat Pelindung Diri}

Tabel 8. Hubungan Ketersediaan Sarana Terhadap Penggunaan Alat Pelindung Diri pada Pekerja Teknisi Mesin di PT PLN Rayon Tembilahan.

\begin{tabular}{|c|c|c|c|c|c|c|c|}
\hline \multirow[b]{2}{*}{ 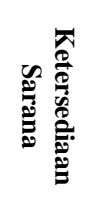 } & \multicolumn{4}{|c|}{ Alat Pelindung Diri } & \multirow[b]{2}{*}{$\overrightarrow{\vec{E}}$} & \multirow{2}{*}{ 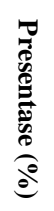 } & \multirow[b]{2}{*}{ 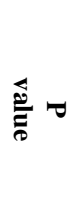 } \\
\hline & 莺. & 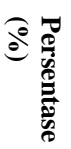 & 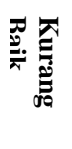 & 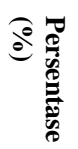 & & & \\
\hline Baik & 9 & 75.0 & 3 & 25.0 & 12 & 100 & \\
\hline $\begin{array}{l}\text { Kurang } \\
\text { baik }\end{array}$ & 7 & 30.4 & 16 & 69.6 & 23 & 100 & 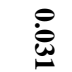 \\
\hline Total & 46 & 82.1 & 10 & 17.9 & 56 & 100 & \\
\hline
\end{tabular}

Berdasarkan Tabel 8, dari 12 pekerja ketersediaan sarana yang baik dalam pengunaan APD sebanyak 9 (75,0\%) dan kurang baik $3(25,0 \%)$ dan 23 pekerja mengatakan ketersediaan sarana yang kurang baik dalam pengunaan APD 7 $(30,4 \%)$ baik dan kurang baik $16(69,6 \%)$

Hasil uji chi-square diperoleh nilai $(0,031<$ $0,05)$ artinya adanya hubungan antara ketersediaan sarana dengan penggunaan APD pada pekerja teknisi mesin di PT PLN Rayon Tembilahan. Dari hasil uji statistik diperoleh nilai OR $(95 \% \mathrm{Cl})=6.857(1.412-$ 33.289) artinya menunjukan bahwa ketersediaan sarana yang kurang baik mempunyai peluang 7 kali berisiko dalam mengunakan APD.

\section{d. Hubungan Pengawasan dengan Pengunaan Alat Pelindung Diri}

Tabel 9. Hubungan Pengawasan Terhadap Pengunaan Alat Pelindung Diri pada Pekerja Teknisi Mesin di PT PLN Rayon Tembilahan.

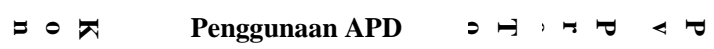




\begin{tabular}{|c|c|c|c|c|c|c|}
\hline & 萨 & 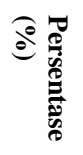 & 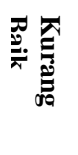 & 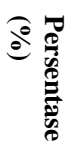 & & \\
\hline Baik & 9 & 50.0 & 9 & 50.0 & 18 & 100 \\
\hline $\begin{array}{l}\text { Kurang } \\
\text { baik }\end{array}$ & 7 & 41.2 & 10 & 58.8 & 17 & 100 \\
\hline Total & 16 & 45.7 & 19 & 54.3 & 35 & 100 \\
\hline
\end{tabular}

Berdasarkan Tabel 9, dari 18 pekerja mengatakan bahwa pengawasan baik dalam pengunaan APD $9(50,0 \%)$ baik dan tidak baik $9(50,0 \%)$ dan pengawasan yang kurang baik dalam penguanaan APD $7(41,2 \%)$ dan kurang baik $10(58,8 \%)$.

Hasil uji chi-square diperoleh nilai $(0,854>$ $0,05)$ artinya tidak adanya hubungan antara pengawasan dengan penggunaan APD pada pekerja teknisi mesin di PT PLN Rayon Tembilahan. Dari hasil uji statistik diperoleh nilai OR $(95 \% \mathrm{Cl})=1.429(0.375-5.437)$ artinya menunjukan bahwa pengawasan yang kurang baik mempunyai peluang $1 \mathrm{kali}$ berisiko dalam mengunakan APD.

\section{PEMBAHASAN}

\section{Hubungan Pengetahuan Terhadap Penggunaan APD (Alat Pelindung Diri)}

Berdasarkan analisis data yang diperoleh dengan menggunakan uji chi-square diketahui tidak terdapat hubungan antara pengetahuan terhadap penggunaan APD, dimana Pvalue yaitu: 0,899 > 0,05. Hasil penelitian ini terbukti bahwa dari penelitian hasil pengetahuan terhadap penggunaan Alat Pelindung Diri (APD) 16 responden berpengetahuan baik dan 19 berpengetahuan kurang baik. Pengetahuan merupakan hasil dari tahu, dan ini terjadi setelah orang melakukan penginderaan terhadap suatu objek tertentu.

Penginderaan terjadi melalui panca indera manusia, yakni indera penglihatan, pendengaran, penciuman, rasa, dan raba. Sebagian besar pengetahuan manusia diperoleh melalui mata dan telinga (Notoatmodjo, 2012: 97). Berdasarkan hasil penelitian yang telah dilakukan, peneliti berpendapat bahwa pengetahuan tentang
APD memiliki peranan dalam pengunaan APD pada pekerja. Jika pekerja mengetahui penggunaan APD tetapi tidak melaksanakannya maka risiko atau bahaya tetap saja akan menimpa pada pekerja itu sendiri.

\section{Hubungan Lingkungan Kerja Terhadap Penggunaan APD (Alat Pelindung Diri)}

Berdasarkan data yang diperoleh dengan menggunakan uji chi-square diketahui terdapat hubungan antara lingkungan kerja terhadap pengunaan APD, dimana Pvalue yaitu: $0,022<0,05$. Analisis keeratan hubungan dua variabel didapatkan nilai Odds Ratio $(\mathrm{OR})=8.500(95 \% \mathrm{CI}=1.458$ 49.539) yang artinya lingkungan kerja yang kurang baik memiliki peluang 8 kali berisiko terhadap pengunaan APD. Hasil penelitian ini terbukti bahwa dari penelitian hasil kondisi lingkungan terhadap penggunaan APD 10 responden baik dan 25 kurang baik.

Lingkungan yang dimaksud adalah lingkungan kerja yang mempunyai pengaruh langsung pada pekerjaan yang dilakukan oleh karyawan. Lingkungan kerja sama artinya dengan kondisi fisik tempat kerja (Tarwaka, 2015:46). Hasil penelitian ini sejalan dengan penelitian sebelumnya yang dilakukan oleh Bustanul Arifin, dkk (2013), dengan hasil penelitian yang diperoleh bahwa terdapat hubungan antara kondisi lingkungan kerja dengan penggunaan alat pelindung diri (APD).

Berdasarkan hasil penelitian yang dilakukan, bahwa kondisi lingkungan yang ada dilapangan kurang baik, Berdasarkan hasil tersebut peneliti berasumsi bahwa kondisi lingkungan yang kurang baik maka dapat menimbulkan bahaya bagi pekerja itu sendiri begitu pula sebaliknya jika kondisi lingkungan yang baik maka pekerja dapat dengan nyaman melakukan pekerjaan tanpa takut terjadinya kecelakaan kerja. 


\section{Hubungan Antara Ketersediaan Sarana dengan Penggunaan APD (Alat Pelindung Diri)}

Berdasarkan data yang diperoleh dengan menggunakan uji chi-square diketahui terdapat hubungan antara ketersedian sarana denga penggunaan APD (alat pelindung diri), dimana Pvalue yaitu: 0,031 $<0,05$. Analisis keeratan hubungan dua variabel didapatkan nilai Odss Ratio $(\mathrm{OR})=6.857$ $(95 \% \mathrm{CI}=1.412-33.289)$ yang artinya ketersediaan sarana kurang baik memilki 7 peluang 7 kali berisiko terhadap pengunaan APD. Hasil penelitian ini terbukti bahwa dari penelitian hasil ketersediaan sarana terhadap penggunaan APD 12 responden baik dan 23 kurang baik. Ketersediaan APD merupakan faktor lingkungan yang sangat penting untuk terbentuknya perilaku seseorang, bila pekerja menggunakan APD yang ada maka dapat mencegah risiko dan bahaya yang ada di tempat kerja.

Dari hasil penelitian yang diperoleh, peneliti berpendapat bahwa sarana prasarana memiliki peranan yang sangat penting dalam penunjang pengunaan APD pada pekerja. Jika sarana prasarana disuatu perusahaan memadai, maka pekerja pada suatu perusahaan akan lebih mudah dalam bekerja dan mengetahui fungsi dari APD tersebut begitupun sebaliknya.

\section{Hubungan Antara Pengawasan Terhadap Penggunaan APD (Alat Pelindung Diri)}

Berdasarkan data yang diperoleh dengan menggunakan uji chi-square diketahui terdapat hubungan antara pengawasan terhadap penggunaan APD, dimana Pvalue yaitu $0,854>0,05$. Analisis keeratan hubungan dua variabel didapatkan nilai Odss Ratio $(\mathrm{OR})=1.429(95 \% \mathrm{CI}=0.375-5.437)$ yang artinya pengawasan yang yang kurang baik mempunyai peluang 1 kali berisiko terdapat penggunaan APD Hasil penelitian ini terbukti bahwa dari penelitian hasil pengawasan terhadap penggunaan APD 18 responden menjawab baik dan 17 responden kurang baik.

Pengawasan adalah mendorong semangat bawahan melaksanakan tugas dalam arti yang luas. Maksud dari pengawas adalah lapisan pengawas dalam organisasi manajemen, atau kepala-kepala dari organisasi yang ada di lapisan bawah. Mereka secara lansung mengaturbahan, sarana, mesin dan peralatan di tempat kerja. Pelaksanaan tugas tersebut dengan pasti juga diberikan tangggung jawab dan wewenang (Tardianto, 2005:275).

Berdasarkan hasil penelitian pengawasan yang dilakukan di PT PLN Rayon Tembilahan sudah baik, pengawasan dari pekerjaan maupun pengawasan dalam segi tata tertib pemakaian APD. Peneliti berpendapat bahwa pengawasan memiliki peranan penting dalam penggunaan APD pada pekerja. Jika pengawasan pada suatu perusahaan kurang, maka pekerja akan lengah dan lalai pentingnya pengunaan APD pada saat bekerja dan tentu saja dapat mengakibatkan kerugian bagi pekerja maupun perusahaan.

\section{KESIMPULAN}

1. Tidak terdapat hubungan antara pengetahuan dengan penggunan APD pada pekerja teknisi mesin di PT PLN Rayon tembilan tahun 2017 (Pvalue = 0,899 . OR $=1.375, \mathrm{Cl} 95 \%=0.361-$ 5.240) dengan 16 responden berpengetahuan baik dan 19 berpengetahuan kurang baik.

2. Terdapat hubungan kondisi lingkungan dengan penggunan APD pada pekerja teknisi mesin di PT PLN Rayon tembilan tahun 2017 (Pvalue $=0,022$ OR 8.500, $\mathrm{Cl} 95 \%=1.458-49.539)$ dengan 10 responden menjawab baik dan 25 responden menjawab kurang baik.

3. Terdapat hubungan ketersediaan sarana dengan penggunan APD pada pekerja teknisi mesin di PT PLN Rayon 
Faktor yang Berhubungan dengan Penggunaan APD pada Pekerja Teknisi (Firman Edigan)

tembilan tahun 2017 (Pvalue $=0,031$ OR 6.857, $\mathrm{Cl} 95 \%=1.412-33.289$ ) dengan 12 responden menjawab baik dan 23 responden menjawab kurang baik.

4. Tidak terdapat hubungan antara pengawasan dengan penggunan APD pada pekerja teknisi mesin di PT PLN Rayon tembilan tahun 2017 (Pvalue $=$ $0,854$ OR 1.429, $\mathrm{Cl} 95 \%=0.375-5.437)$ dengan 18 responden menjawab baik dan 17 responden menjawab kurang baik.

\section{SARAN}

\section{Bagi PT. PLN Rayon Tembilahan}

Kepada pihak PT PLN Rayon Tembilahan untuk lebih memperhatikan kondisi lingkungan (penempatan alat/ pembersihan oli yang tumpah) dan penambahan ketersediaan APD (Alat Pelindung Diri) seperti safety helmet, dace shilet, safety ear plug \& ear muff, safety hand, safety clothes, safety shoes, untuk keseluruhan para pekerja agar dapat mengurangi risiko dari kecelakaan saat bekerja dan untuk menjaga keselamatan dan kesehatan para pekerja.

\section{Bagi STIKes Hang Tuah Pekanbaru}

Dapat bermanfaat dan menambah bahan bacaan dan referensi bagi mahasiswa di perpustakaan serta dapat dijadikan wawasan atau bahan referensi penelitian bagi peneliti selanjutnya, dengan menambahkan variabel sehingga diharapkan dapat memperkuat hasil penelitian.

\section{Bagi Peneliti Selanjutnya}

Kepada peneliti yang tertarik dengan penelitian ini agar dapat melakukan penelitian dengan variabel yang berbeda dengan aspek-aspek yang lebih luas lagi untuk menyempurnakan penelitian ini.

\section{DAFTAR PUSTAKA}

Anizar. (2012). Teknik Keselamatan dan Kesehatan Kerja di Industri: Yogykarta: Graha ilmu.

Buntarto, (2015). Panduan Praktis Keselamatan Kesehatan dan Kerja untuk Industri. Yogyakarta: Pustaka baru press.

Bustanul Arifin dan Arif Susanto. (2013). Faktor-Faktor yang Berhubungan dengan Kepatuhan Pekerja Dalam Pemakaian Alat Pelindung Diri (APD) di Bagian Coal Yard X Unit 3 \& 4 Kabupaten Jepara Tahun 2012 (vol. 2, No. 1 Mei 2013).

BPJS Ketenagakerjaan Tahun 2015 dari: [http://www.bpjsketenagakerjaan. go. Id/berita kecelakaan kerja]. Diakses 02 Juli 2017.

Dewi M. \& Wawan A. (2011) Teori \& pengukuran Pengetahuan Sikap dan Perilaku Manusia, Yogyakarta: Nuha Medika.

ILO.2013.

http://industri.bisnis.com/read/201 30115/12/131146/kecelakaankerja-ilo-laporkan-kasus-di-riterbilang-tinggidiakses pada 27 Februari 2017.

Kurniawati, D. (2013). Taktis Memahami Keselamatan dan Kesehatan Kerja Bidang Teknologi Informasi, Surakarta: Aksara Sinergi Media.

Notoatmodjo. (2012). Promosi Kesehatan dan Perilaku Kesehatan, Jakarta: Rineka Cipta.

Daroyono B, 2014. Mengenal alat pelindung diri, Pusdiklat K3 diakses: pada Tanggal 27 Juli 2017

Peraturan Undang Undang tentang Pemakaian Alat Pelindung Diri pasal 14 NO.1 Tahun 1970 (2012). (Online). Diakses Tanggal 12 Maret 2018. 
Rijanto. (2011). Pedoman Pencegahan Kecelakaan di Industri, jakarta: mitra wacana media

Tardianto, T. (2005). Sistem Manajemen dan Standar Pemeriksaan Keselamatan dan Kesehatan Kerja (K3).PB Panca Bhakti, Jakarta.

Tarwaka. (2015). Keselamatan, Kesehatan Kerja dan Ergonomi K3 Dalam Persektif Bisnis, Surakarta: harapan press

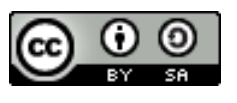

This is an open access article which means that all content is freely available without charge to the user or his/her institution. Jurnal Saintis allows the author(s) to hold the copyright without restriction. The copyright in the text of individual articles (including research articles, opinion articles, and abstracts) is the property of their respective authors distributed under the terms of the Creative Commons Attribution-ShareAlike 4.0 International License(https://creativecommons.org/licenses/by-sa/4.0/) which permits unrestricted use, distribution, and reproduction in any medium. Users are allowed to read, download, copy, distribute, search, or link to full-text articles in this journal without asking by giving appropriate credit, provide a link to the license, and indicate if changes were made. 
J. Saintis Volume 18 Nomor 1, 2018

Halaman ini sengaja dikosongkan 